\title{
VIHREÄN PARSAN VILJELY- JA LAJIKEKOE V. 1960-71
}

\author{
Irma Suhonen \\ Helsingin yliopiston puutarhatieteen laitos \\ Saapunut 31.5. 1972 \\ GROWING AND VARIETY TRIAL WITH GREEN ASPARAGUS \\ IRMA SUHONEN \\ Institute of Horticulture, University of Helsinki
}

\begin{abstract}
The growing of green asparagus and the varietal differences of 3 varieties (Connover's Colossal, Dansk Kampe, Schneekopf) and 5 improved selections of Washingtontype from Davis University, California, were studied in 1960-71. The asparagus was sown in 1960, and planted out in 1961 or 1962 . The crowns were spaced $120 \mathrm{~cm}$ between rows and $50 \mathrm{~cm}$ between plants. The spears were cut at the surface when $12-22 \mathrm{~cm}$ or $12-18 \mathrm{~cm}$ long.

In 1965-71 the harvesting season began 14-20th May and lasted 12-31 days. During this seven years period the average yield was $25 \mathrm{~kg} / \mathrm{a}$. In $1965-68$ the earlier planting gave bigger yields than the later one. Varieties Schneekopf and Connover's Colossal gave the highest yields, in average $31 \mathrm{~kg} / \mathrm{a}(16-48 \mathrm{~kg} / \mathrm{a})$. The yields of all improved strains were lower than those of old varieties. The average weight of a single spear varied according to variety and maximum length from 16.0 to $22.5 \mathrm{~g}$. The dry matter content of green asparagus was $7.7-8.2 \%$, the fiber content $2.8-3.4 \%$, the ascorbic acid content $42-$ $55 \mathrm{mg} / 100 \mathrm{~g}$ and the B-carotin content $580-1180 \mu \mathrm{g} / 100 \mathrm{~g}$.
\end{abstract}

Parsaa tuotetaan vihreänä tai valkoisena. Valkeaa parsaa tuotettaessa maan pinta muodostetaan harjuiksi, joiden sisältä »valkeat» parsanversot korjataan. Vihreätä parsaa taas viljellään tasamaalla, ja sadonkorjuu tapahtuu versojen tultua maan pinnalle. Vihreän parsan viljely asettaakin pienemmät vaatimukset maan rakenteen suhteen kuin valkean parsan viljely, ja siinä työvaiheet ovat yksinkertaisemmat ja työmenekki muodostuu vähäisemmäksi. Niinpä Euroopassa, missä traditionaalisesti on tuotettu valkeaa parsaa, kiinnostus vihreän parsan viljelyyn on kasvamassa (REINHold ja KRÜGER 1960, FrankeN ja Backus 1968, Myklebust 1968).

Suomessa ei parsan viljelyä ole merkittävissä määrin harjoitettu. Kevätkesään ajoittuvan satokautensa vuoksi se voi kuitenkin sopivasti täydentää avomaan vihanneskasvivalikoimaamme. Tämän vuoksi ja koska vihreän parsan viljelystä ei maassamme aikaisempia kokemuksia ole, suoritettiin Helsingin yliopiston puutarhatieteen laitoksella Viikissä v. 1960—71 tutkimus, jossa selvitettiin vihreän parsan menetelmän soveltuvuutta oloihimme, taimien iän merkitystä sekä eräiden lajikkeiden ja kantojen satoisuutta ja laatuominaisuuksia. 


\section{Aineisto ja menetelmät}

Viljeltävänä oli kolme parsalajiketta (Connover's Colossal, Schneekopf ja Dansk Kæmpe) sekä viisi G. Hannan erityisesti vihreän parsan viljelyä varten jalostamaa kantaa: 309(14), 500W(1), 500W(3), 711(9) ja 873(1). Viimeksimainittujen peruslajikkeena on Mary Washington, ja niiden siemenet saatiin Davis'in yliopistolta Kaliforniasta.

Taimikasvatusta varten parsa kylvettiin avomaalle 17.5.1960, ja se istutettiin varsinaiselle kasvupaikalle toukokuun viimeisellä viikolla v. 1961 (lohko I) ja v. 1962 (lohko II). Riviväli oli $120 \mathrm{~cm}$ ja taimiväli rivissä $50 \mathrm{~cm}$. Kerranteita oli molemmilla lohkoilla neljä ja taimimäärä kerranteessa 10 .

Kasvualustaan, mHHt, annettiin syksyllä v. 1960 kalkkikivijauhetta 2 tn/ha sekä karjanlantaa $3 \mathrm{tn} / \mathrm{ha}$. Koetta perustettaessa levitettiin $4 \mathrm{~kg}$ kaliumsulfaattia, $6 \mathrm{~kg}$ superfosfaattia sekä $2 \mathrm{~kg}$ oulunsalpietaria aarille.

Istutusvuoden jälkeen parsamaan lannoitus oli vuosittain seuraava: Keväällä ennen versojen esiintuloa levitettiin $4 \mathrm{~kg} / \mathrm{a}$ kalisuolaa, $2 \mathrm{~kg} / \mathrm{a}$ superfosfaattia sekä $2 \mathrm{~kg} / \mathrm{a}$ oulunsalpietaria. Sadonkorjuun päätyttyä annettiin pintalannoituksena kaksi kertaa $3 \mathrm{~kg} / \mathrm{a}$ kalkkisalpietaria. Tämän lisäksi v. 1965 - 66 koealalle levitettiin booraksia 150 g/a. Rikkakasvien torjunta tapahtui mekaanisesti.

Parsan sadonkorjuu aloitettiin v. 1964, jolloin satoa kerättiin 23-30.5. Vuosittain korjuuseen ryhdyttiin heti ensimmäisten versojen ilmaannuttua maan pinnalle, 14-20. toukokuuta. Sadonkorjuuaika oli eri vuosina seuraava: v. 196512 vrk, 1966-67 18-20 vrk, v. 1968-69 23-26 vrk sekä v. 1970-71 31 vrk. Joka toinen tai joka kolmas päivä tapahtuvan korjuun yhteydessä kerättiin kaikki vähintään $12 \mathrm{~cm}: n$ mittaiset versot, jotka leikattiin maan pinnan tasalta. Versojen maksimipituudeksi määrättiin $22 \mathrm{~cm}$ (v. 1964 69) tai $18 \mathrm{~cm}$ (v. 1970-71). Tätä pitemmät versot typistettiin tyvestä käsin maksimipituuteen, minkä jälkeen suoritettiin seuraavat määritykset: kokonaissato (v. 1964-71), verson paino (v. 1964-71), verson keskiosan läpimitta (v. 1965-67), silmävarainen laatuluokitus (v. 1968-71), kuiva-ainepitoisuus (v. 1965-68), kuitupitoisuus (v. 196566), sekä askorbiinihappo- ja $\beta$-karotiinipitoisuus (v. 1966).

\section{Tulokset}

Vuonna 1964, jolloin satoa korjattiin viikon ajan, saatiin lohkosta I keskimäärin 4.1 kg/a ja lohkosta II $2.7 \mathrm{~kg} / \mathrm{a}$ parsanversoja. V. 1965-71 parsan keskimääräinen kokonaissato oli lohkolla I $25.2 \mathrm{~kg} / \mathrm{a}$ ja lohkolla II $25.1 \mathrm{~kg} / \mathrm{a}$ (taulukko 1). Lohkosta I saatiin v. 1964-68 enemmän satoa kuin lohkosta II, sen sijaan v. 1970-71 lohkon II sato oli suurempi.

Varhaisen toukokuun aikana saadun sadon määrä vaihteli eri vuosina $2.6-20.2 \mathrm{~kg} / \mathrm{a}$, mikä johtui kulloinkin vallinneista lämpöoloista. Lohkosta II saatu aikainen sato oli yleensä suurempi kuin lohkosta I saatu (taulukko 1).

Parsalajikkeiden ja -kantojen satoisuuserot olivat huomattavat (taulukko 2). Eniten satoa saatiin lajikkeesta Schneekopf (keskimäärin 31.7 kg/a) ja Connover's Colossal (keskimäärin $31.4 \mathrm{~kg} / \mathrm{a}$ ). Varsinaisten lajikkeiden kokonaissato oli suurempi kuin numerokantojen, joista parhaan kokonaissato oli keskimäärin $25.7 \mathrm{~kg} / \mathrm{a}$ ja heikoimman $17.9 \mathrm{~kg} / \mathrm{a}$. Lajikkeet olivat aikaissatoisempia kuin uudet vihreän parsan kannat. V. 1968, jolloin toukokuu oli poikkeuksellisen kylmä, kaikkien lajikkeiden aarisadot muodostuivat pie- 
Taulukko 1. Parsan kokonaissato (kg/a) lohkoilla I ja II sekä toukokuun aikana saatu sato (kg/a), v. 1965-71.

Table 1. The total yield (kg/a) of one-year-old (plants I) and of 2-year-old (plants II) crowns and the early yield harvested in May, in 1965-71.

\begin{tabular}{|c|c|c|c|c|c|c|c|c|}
\hline \multirow{3}{*}{$\begin{array}{l}\text { Lohko } \\
\text { Plants }\end{array}$} & \multicolumn{7}{|c|}{ Kokonaissato $\mathrm{kg} / \mathrm{a}$} & \multirow{3}{*}{$\begin{array}{c}\text { Keskimäärin } \\
\text { Average } \\
\text { kg/a }\end{array}$} \\
\hline & \multicolumn{7}{|c|}{ Total yield $\mathrm{kg} / \mathrm{a}$} & \\
\hline & -65 & -66 & -67 & -68 & -69 & -70 & -71 & \\
\hline I & 17.3 & 20.0 & 29.2 & 23.1 & 22.6 & 30.7 & 33.3 & 25.2 \\
\hline \multirow[t]{3}{*}{ II } & 14.0 & 17.3 & 28.3 & 22.1 & 22.5 & 33.4 & 38.4 & 25.1 \\
\hline & $\overline{15.7}$ & $\overline{18.7}$ & $\overline{28.8}$ & $\overline{22.6}$ & $\overline{22.6}$ & $\overline{32.1}$ & $\overline{35.9}$ & $\overline{25.2}$ \\
\hline & \multicolumn{7}{|c|}{$\begin{array}{c}\text { Toukokuun sato } \mathrm{kg} / \mathrm{a} \\
\text { Early yield } \mathrm{kg} / \mathrm{a}\end{array}$} & \\
\hline I & - & 4.8 & 20.2 & 2.6 & 6.1 & 5.4 & 13.0 & 8.7 \\
\hline II & - & 8.0 & 19.7 & 2.8 & 6.3 & 7.4 & 16.7 & 10.2 \\
\hline
\end{tabular}

Taulukko 2. Parsalajikkeitten ja -kantojen kokonaissato (kg/a) v. 1965-71 ja toukokuun aikana saatu sato $(\mathrm{kg} / \mathrm{a})$ v. 1966-71. Tulokset keskiarvoja lohkoilta I ja II.

Table 2. The total yield ( $\mathrm{kg} / \mathrm{a})$ of different asparagus varieties and strains in $1965-71$ and the amount of yield harvested in May, in 1966-71.

\begin{tabular}{|c|c|c|c|c|c|c|c|c|c|}
\hline \multirow[t]{2}{*}{$\begin{array}{l}\text { Kanta tai lajike } \\
\text { Strain or variety }\end{array}$} & \multicolumn{7}{|c|}{$\begin{array}{c}\mathrm{Kok} \text { on a issato } \mathrm{kg} / \mathrm{a} \\
\text { Totalyield } \mathrm{kg} / \mathrm{a}\end{array}$} & \multirow{2}{*}{$\begin{array}{c}\text { Keskim. } \\
\text { Mean } \\
\text { kg/a }\end{array}$} & \multirow{2}{*}{$\begin{array}{l}\text { Toukok. } \\
\text { In May } \\
\text { kg/a }\end{array}$} \\
\hline & -65 & -66 & -67 & -68 & -69 & -70 & -71 & & \\
\hline Schneekopf & 17.6 & 23.0 & 33.0 & 29.2 & 31.6 & 39.4 & 48.1 & 31.7 & 13.0 \\
\hline Connover's Colossal & 16.1 & 25.7 & 32.5 & 28.6 & 30.0 & 39.8 & 47.1 & 31.4 & 14.6 \\
\hline Dansk Kæmpe & 15.1 & 20.4 & 28.6 & 26.6 & 25.6 & 39.0 & 46.4 & 28.8 & 11.8 \\
\hline $500 \mathrm{~W}(3)$ & 17.2 & 20.5 & 33.9 & 22.8 & 23.1 & 31.5 & 31.2 & 25.7 & 9.2 \\
\hline $873(1)$ & 15.3 & 13.4 & 25.1 & 22.3 & 26.6 & 30.4 & 35.4 & 24.1 & 7.4 \\
\hline $500 \mathrm{~W}(1)$ & 16.2 & 15.5 & 29.8 & 19.5 & 20.4 & 28.2 & 27.4 & 22.4 & 7.3 \\
\hline $711(9)$ & 14.7 & 18.2 & 26.7 & 16.4 & 14.7 & 23.6 & 26.0 & 20.0 & 7.1 \\
\hline $309(14)$ & 13.2 & 12.3 & 20.5 & 15.3 & 14.1 & 24.6 & 25.2 & 17.9 & 5.4 \\
\hline
\end{tabular}

nemmiksi kuin edellisenä vuonna. Vihreän parsan kannoilla 500W(1), 500W(3) jä 711(9) aarisato oli tällöin yli $10 \mathrm{~kg}$ edellisenä vuonna saatua pienempi.

Parsan verso painoi v. 1965 - 69, jolloin verson maksimipituus määrättiin $22 \mathrm{~cm}: \mathrm{ksi}$, keskimäärin 20.6 g. V. 1970—71, jolloin maksimipituus oli $18 \mathrm{~cm}$, verson keskimääräinen paino oli $17.3 \mathrm{~g}$. Vihreän parsan kannoista saatiin keskimäärin painavampia versoja kuin vanhoista lajikkeista (taulukko 3). Painavimmiksi todettiin kantojen 500W(3) ja 873(1) versot, ja keveimmät versot saatiin lajikkeesta Dansk Kæmpe. Tukevien, läpimitaltaan yli $12 \mathrm{~mm}: \mathrm{n}$ versojen osuus kokonaissadosta oli vihreän parsan kannoilla sưurempi (57$69 \%$ ) kuin lajikkeilla (46-53\%). Silmävaraisessa lajittelussa versot luokiteltiin A-luokkaan (läpimitaltaan vähintään $10 \mathrm{~mm}$ olevat suorat, terveet versot) ja B-luokkaan (läpimitaltaan alle $10 \mathrm{~mm}$ olevat tai vioittuneet versot). V. 1965-67 todettiin, että läpirnital. 
Taulukko 3. Verson keskimääräinen paino v. 1965-69 ja 1970—71, sadon jakautuma verson läpimitan mukaan v. 1965-67 sekä lajittelutulos v. 1968-71.

Table 3. The average weight of spear in 1965-69 and in 1970-71, the classifying results ( $\%$ of total yield) on diameter of the spear in 1965-67 and the grading results for grade A (= prima) and for grade B (spears less than $10 \mathrm{~mm}$ in diameter or injured) in $1968-71$.

\begin{tabular}{|c|c|c|c|c|c|c|c|}
\hline \multirow[t]{2}{*}{$\begin{array}{l}\text { Kanta tai lajike } \\
\text { Strain or variety }\end{array}$} & \multicolumn{2}{|c|}{$\begin{array}{l}\text { Verson paino } \mathrm{g} \\
\text { Spear weight } \mathrm{g}\end{array}$} & \multicolumn{3}{|c|}{$\begin{array}{c}\text { Verson läpimitta } \\
\text { Diameter of spear } \\
<10 \mathrm{~mm} 10-12 \mathrm{~mm}>12 \mathrm{~mm}\end{array}$} & \multicolumn{2}{|c|}{$\begin{array}{l}\text { Lajitelma } \\
\text { Grades }\end{array}$} \\
\hline & $1965-69$ & $1970-71$ & $\begin{array}{c}<10 \mathrm{~m} \\
\%\end{array}$ & $\begin{array}{r}-12 \\
\% \\
\end{array}$ & $\begin{array}{c}>12 \mathrm{~mm} \\
\%\end{array}$ & A $\%$ & B \% \\
\hline $500 \mathrm{~W}(3)$ & 22.5 & 18.2 & 14 & 17 & 69 & 71 & 29 \\
\hline $873(1)$ & 22.2 & 19.1 & 17 & 18 & 65 & 71 & 29 \\
\hline $711(9)$ & 21.5 & 17.2 & 15 & 20 & 65 & 72 & 28 \\
\hline $309(14)$ & 21.5 & 16.9 & 25 & 14 & 61 & 68 & 32 \\
\hline Schneekopf & 20.3 & 18.1 & 20 & 27 & 53 & 70 & 30 \\
\hline $500 \mathrm{~W}(1)$ & 19.8 & 16.8 & 20 & 23 & 57 & 73 & 27 \\
\hline Connover's Colossal & 18.5 & 16.0 & 22 & 30 & 48 & 66 & 34 \\
\hline Dansk Kæmpe & 18.2 & 16.3 & 21 & 33 & 46 & 72 & 28 \\
\hline & $\overline{20.6}$ & $\overline{17.3}$ & $\overline{19}$ & $\overline{23}$ & $\overline{58}$ & $\overline{70}$ & $\overline{30}$ \\
\hline
\end{tabular}

Taulukko 4. Parsan kuiva-ainepitoisuus v. 1965-68, kuitupitoisuus v. 1965-66 sekä askorbiinihappoja $\beta$-karotiinipitoisuus v. 1966.

Table 4. The dry matter (in 1965-68), fiber (in 1965-66), ascorbic acid (in 1966) and $\beta$-carotin (in 1966) contents of green asparagus.

\begin{tabular}{lcccc}
\hline $\begin{array}{l}\text { Kanta tai lajike } \\
\text { Strain or variety }\end{array}$ & $\begin{array}{c}\text { Kuiva-aine } \% \\
\text { Dry matter } \%\end{array}$ & $\begin{array}{c}\text { Kuitu \% } \\
\text { Fiber } \%\end{array}$ & $\begin{array}{c}\text { Ask. happo } \\
\text { Asc. acid } \\
m g / 100 \mathrm{~g}\end{array}$ & $\begin{array}{c}\beta \text {-karotiini } \\
\beta \text {-carotin } \\
\mu \mathrm{g} / 100 \mathrm{~g}\end{array}$ \\
\hline $500 \mathrm{~W}(1)$ & 7.7 & 2.8 & 46 & 780 \\
$309(14)$ & 7.7 & 3.0 & 55 & 750 \\
$711(9)$ & 7.8 & 3.1 & 42 & 580 \\
$873(1)$ & 7.9 & 2.9 & 51 & 700 \\
$500 \mathrm{~W}(3)$ & 7.9 & 3.1 & 49 & 920 \\
Schneekopf & 8.0 & 3.2 & 55 & 1160 \\
Dansk Kæmpe & 8.0 & 3.3 & 49 & 900 \\
Connover's Colossal & $\mathbf{8 . 2}$ & $\underline{3.4}$ & $\underline{52}$ & $\underline{1180}$ \\
& $\overline{7.9}$ & $\mathbf{3 . 1}$ & $\overline{50}$ & 870 \\
\hline
\end{tabular}

taan alle $10 \mathrm{~mm}$ olevien versojen osuus kokonaissadosta oli keskimäärin $19 \%$ ja vioittuneiden osuus $9 \%$, ja B-luokan osuus siis $28 \%$. V. 1968-71 keskimäärin $70 \%$ kokonaissadosta katsottiin A-luokkaan kuuluviksi (taulukko 3).

Parsan kuiva-ainepitoisuus oli keskimäärin $7.9 \%$ (taulukko 4). Vanhoilla lajikkeilla kuiva-ainepitoisuus oli korkeampi $(8.0-8.2 \%)$ kuin uusilla kannoilla (7.7-7.9\%). Myös kuitupitoisuus oli lajikkeilla suurempi kuin kannoilla. Vihreän parsan askorbiinihappopitoisuudeksi todettiin $42-55 \mathrm{mg} / 100 \mathrm{~g}$ ja $\beta$-karotiinipitoisuudeksi $580-1180 \mu \mathrm{g} /$ $100 \mathrm{~g}$. 


\section{Tulosten tarkastelu}

Kirjallisuustietojen mukaan valkean ja vihreän parsan sadot ovat samaa suuruusluokkaa, 20-50 kg/a, keskisadon muodostuessa noin $30 \mathrm{~kg}$ :ksi aarilta (ReINHold ja KRÜGer 1960, HaHn ja Zell 1964). Eurooppalaisissa tutkimuksissa vihreän parsan sato on vaihdellut 10-40 kg/a (Franken ja Backus 1968, Kaufmann 1968, Myklebust 1968). Nyt selostetussa kokeessa 8 parsalajikkeen ja -kannan keskisato oli $25 \mathrm{~kg} / \mathrm{a}$, satoisimpien lajikkeiden keskisato yli $30 \mathrm{~kg} / \mathrm{a}$ ja paras vuotuinen aarisato $48 \mathrm{~kg}$, joten satotasoa voidaan pitää tavanomaisena.

Kaksivuotisina istutettujen taimien sato jäi viitenä satovuonna alhaisemmaksi kuin yksivuotisten taimien sato. Voidaankin todeta, ettei aikaisemmin tärkeänä pidetystä pidennetystä taimikasvatuksesta ole etua (ANON. 1971). Aikaisemmin parsan viljelyssä on myös kolmen vuoden rehevöitymisaikaa ennen sadonkorjuuseen ryhtymistä pidetty välttämättömänä, jota menettelyä tässä tutkimuksessa lohkon I osalta noudatettiin. Nykyisin on kuitenkin pyrkimyksenä lyhentää parsaviljelmän tuottamatonta kautta antamalla kasveille kahden tai vain yhden kasvukauden rehevöitymisaika (ANoN. 1971). Varhain aloitettavaan sadonkorjuuseen liittyen on selvitetty, voidaanko parsan istutustiheyttä suurentamalla satoa pinta-alaa kohden lisätä, ja täten parantaa viljelyn alkuvuosien kannattavuutta. Tulokset ovat tähän asti olleet myönteisiä (KAufManN 1968, Loughton 1970). Istutustiheyden suurentamista puoltaa myös se, että parsaviljelmän vanhetessa osa kasveista tuhoutuu. Niinpä Viikissä oli v. $1970-71$ alkuperäisistä taimista jäljellä $60-65 \%$, ja esim. kanadalaisessa tutkimuksessa on yhdeksäntenä koevuonna todettu $40-50 \%$ taimista tuhoutuneen (Loughton 1970).

Vuotuiseen parsasadon määrään vaikuttaa myös sadonkorjuuajan pituus. Viikissä sadonkorjuuaika oli ensimmäisten neljän satovuoden aikana varsin lyhyt verrattuna vanhaan käytäntöön, jonka mukaan parsan sadonkorjuu lopetetaan juhannukseen mennessä. Sadonkorjuun lopettaminen tätä aikaisemmin ei Saksassa suoritettujen tutkimusten mukaan paranna seuraavan vuoden satoa (BLAsınsky 1969).

Vihreällä parsalla verson paino jää yleensä alhaisemmaksi kuin valkealla (mm. MYKLEBUST 1968), koska se on korjattava valkeata lyhyempänä latvasupun nopean avautumisen ja puutumisen vuoksi. Viikissä todettiin, että $22 \mathrm{~cm}$ :ä pitkä vihreän parsan verso on usein alaosastaan puutunut ja latvasuppu avautumassa. Tutkimuksen viimeisinä vuosina maksimipituus määrättiinkin $18 \mathrm{~cm}$ :ksi. Menettelyä puoltaa alankomaalainen koetulos, jonka mukaan vihreä parsa tulisi leikata ennen kuin verso ylittää $15 \mathrm{~cm}$ :n pituuden (FrANken ja BAckus 1968). Tämä edellyttää päivittäistä korjuuta helteisinä kausina, sillä verso saattaa venyä $9 \mathrm{~cm}$ vuorokaudessa kuituisuuden lisääntyessä voimakkaasti 2 . ja 3 . kehityspäivän välillä (KAUFmanN 1967).

Tässä tutkimuksessa parsalajikkeet osoittautuivat satoisemmiksi kuin uudet vihreän parsan kannat. Näiden välillä ei taimien kuolleisuudessa ilmennyt mainittavia eroavuuksia, sen sijaan aikaisuusero oli selvä lajikkeiden hyväksi. Lajikkeista Connover's Colossal oli lajittelutuloksen suhteen heikoin ja siinä oli korkein kuiva-aine- ja kuitupitoisuus. Norjalaisten kokeiden mukaan tämä lajike on laadultaan parempi valkeana viljeltynä, kun sen sijaan Dansk Kæmpe soveltuu molemmilla tavoin viljeltäväksi (MYKLEBUST 1968). Myös Schneekopf näyttää soveltuvan vihreänä viljeltäväksi. 


\section{Tiivistelmä}

V. 1960-71 suoritettiin Helsingin yliopiston puutarhatieteen laitoksella Viikissä vihreän parsan viljely- ja lajikekoe. Parsa kylvettiin v. 1960 ja istutettiin v. 1961 ja 1962.

V. 1965-71 parsan keskisato oli $25 \mathrm{~kg} / \mathrm{a}$, parhaan lajikkeen keskisato $32 \mathrm{~kg} / \mathrm{a}$ ja heikoimman numerokannan $18 \mathrm{~kg} / \mathrm{a}$. Varhaisen toukokuun aikana saadun sadon määrä vaihteli eri vuosina $2.6-20.2 \mathrm{~kg} / \mathrm{a}$. Kaksivuotisten taimien sato oli tutkimuksen alkuvuosina alhaisempi kuin yksivuotisten taimien, keskisadon koko koeajalta muodostuessa kuitenkin samaksi. Parsanverso painoi keskimäärin $19 \mathrm{~g}$, versoista lähes $60 \%$ oli läpimitaltaan yli 12 mm:n mittaisia. Silmävaraisessa arvostelussa $70 \%$ kokonaissadosta katsottiin ensiluokkaiseksi. Vihreän parsan kuiva-ainepitoisuus oli $7.7-8.2 \%$, kuitupitoisuus $2.8-3.4 \%$ ja se sisälsi $42-55 \mathrm{mg} / 100 \mathrm{~g}$ askorbiinihappoa ja $580-1180 \mu \mathrm{g} / 100 \mathrm{~g} \beta-$ karotiinia.

Selostetun kokeen perusti ja hoiti v. 1960-62 maisteri Lea Kurki, v. 1963-66 koetta hoiti maisteri Kirsti Osara.

\section{KIRJALLISUUTTA}

Anon. 1971. Commercial growing of asparagus. US. Dept. Agr. Farmer's Bull. 2232. 22 p.

Blasinsky, J. 1969. Stechzeitenversuche bei Spargel. Gemüse 5: 120.

HAнN, M. \& Zell, H. 1964. Spargelanbau. 82 p. Stuttgart.

Franken, A. A. \& BACkus, C. T. G. 1968. Onderzoek naar de mogelijkheid van de teelt groene asperge in Nederland. Meded. Proefstat. Groent. Alkmaar 44. 31 p.

Kaufmann, F. 1967. Der Einfluss der Wachstumsgeschwindigkeit und -dauer auf die Faserigkeit von grünen Spargeltrieben. Arch. für Gartenb. 15: 89-100.

Kaufmans, F. 1968. Höhere Grünspargelerträge durch engere Standweiten. Deut. Gartenb. 15: 42-44.

Lovgrton, A. 1970. Effects of plant spacing on yield of asparagus. Ontario Hort. Res. Inst. Rep. 1970, p. $65-74$.

MyкцEвUst, E. 1968. Sortforsek med asparges. Norges Landbrukshøgskole, Inst. Grønsakdyrking, Meld. 28, 7 p.

ReINHOLD, J. \& KrÜGer, K. 1960. Grünspargel. 64 p. Berlin. 